\title{
Leveraging Communities of Practice as Professional Learning Communities in Science, Technology, Engineering, Math (STEM) Education
}

\author{
Amanda L. Glaze-Crampes \\ 4105 College of Education Building, Georgia Southern University, P.O. Box 8013, Statesboro, GA 30460, USA; \\ aglaze@georgiasouthern.edu
}

Received: 29 May 2020; Accepted: 21 July 2020; Published: 23 July 2020

\begin{abstract}
In the modern educational era, there is an increasing focus on Science, Technology, Engineering and Math (STEM) education. Innovation and workforce preparation play a large role in the push to increase scientific literacy, thinking skills and high-skilled personnel. However, there are ongoing issues with reforming education to meet these goals as well as the recruitment and retention of students in these fields. STEM and the various other iterations in which it is found, represents a challenge in education, as there are often many intersecting cultures, epistemologies, practices and expectations that are unique to each of the represented fields. As a result, educators often struggle with creating STEM experiences and programs that truly integrate each of the disciplines in a meaningful way. This discussion explores the potential role of leveraging existing communities of practice into Professional Learning Communities in order to shift the attention toward student experiences while more clearly defining the goals, roles and expectations in STEM.
\end{abstract}

Keywords: STEM; communities of practice; professional learning communities

\section{Introduction}

Science, technology, engineering, and mathematics (STEM) education remains a critical area of need when it comes to recruitment, retention and reform in education [1-4]. One of the challenges of bringing about change in STEM is the complexity that comes as a result of many intersecting fields, each with its own epistemology, culture and practice [5]. Each field represented in STEM is made up of communities of practice, expert communities that share goals, structures, expectations and practices [6]. These communities of practice are generally oriented to sharing culture and knowledge within the community but can be used for reform by shifting to a focus on student outcomes, thus becoming professional learning communities. Leveraging intersecting communities of practice to build professional learning communities that have varying levels of expertise, representation of each of the included fields and involve experts and education could represent a transformative tool in STEM education.

Professional Learning Communities (PLCs) and Science, Technology, Engineering and Math (STEM) are educational buzzwords in the 21st century but are not new concepts. As Kezar, Gehrke and Bernstein-Sierra noted, numerous entities, including the American Association for the Advancement of Science [7], have been calling for reform in STEM education at the university and earlier levels due to decreases in interest and dismal retention levels [5] (p. 217). In the United States, one would be hard-pressed to find school districts that do not have established PLCs to tackle a variety of issues regarding student performance or that do not put at least some effort into STEM integration in the curriculum. One of the underlying issues with STEM education is that there exist a variety of definitions of STEM and what it should look like in practice. In higher education, STEM disciplines represent fields 
that are often housed in separate colleges within a university, adding another layer of complication to conversations about what STEM is and what it represents [5].

Communities of practice are existing structures within disciplines of science, technology, engineering and mathematics, as well as in many other fields. They exist where experts are brought together to share knowledge and practices of a shared field and where shared goals or outcomes are present. Professional learning communities are similar in that they represent collections of experts with shared goals but are sharply differentiated by the specific goal of positively impacting student learning and outcomes. STEM education represents a place where these two elements of community funds of knowledge can be merged, bringing together communities from existing fields that are represented but in new ways and with a new goal—student outcomes. The creation of communities of practice that are also professional learning communities requires the representation of players from all STEM elements. These members must be willing to share their existing disciplinary cultures in new ways and work together to build an interdisciplinary community for the benefit and growth of students entering those fields. Community building can be challenging where cultures are seen as tight-knit communities with little entry or access and requires that representatives be aware and able to compromise to build a new culture that integrates existing norms, expertise and practices that are different from their own.

\section{Review of Literature}

\subsection{Theoretical Background}

Learning communities are founded upon social and sociocultural learning theories, situated knowledge and learning theories, and the apprenticeship theory of legitimate peripheral participation [8-10]. Social learning traces its ancestry to constructivism, in its view that "learning is a social process of making sense of experience in terms of what is already known" [11,12] (p. 10). The keys to understanding how communities of practice and learning connect are based on three assumptions: knowledge is a social process, knowledge is situated in a real-world context and learning takes place not only in formal settings but also through interactions with others and the development of meaning, cultural languages and artifacts of their practice [13].

According to Anderson, "sociocultural research in science education brings together ideas and practice from several longstanding intellectual traditions" [8] (p. 14). Lave and Wenger explain learning in communities of practice as something that is occurring at all times and is a "condition of and evolving form of membership" [10] (p. 53). They are joined by subsequent research in their conclusion that differentiation cannot be made between learning and social interaction and that the two are not mutually exclusive [14,15]. They are reminding us that culture comes from a constant renegotiation of meaning based on our interactions and the response we have to others [16]. Situated learning addresses knowledge, saying that it is "situated" in an authentic context. People learn by interacting with the knowledge as it is applied in the real world, as opposed to learning the same concepts in the confines of a classroom. Authentic learning is exemplified by individuals' ability to informally solve math problems while shopping that, in the classroom, they were unable to solve [9]. Participation in the actual event facilitates learning in the context of usage, as opposed to a theoretical representation such as classroom learning from a textbook.

Legitimate peripheral participation takes a step beyond this situation by adding that competence arises from a situated experience within which a member of a community of practice transcends from beginner to expert through interactions within the culture itself, moving from the "periphery" or access point, to full participation as an accepted or legitimate member [10]. Therefore, communities of practice provide a specific backdrop for learning and immersion in the culture through legitimate peripheral participation. It is important to note that there is no specific position within a community that serves as the expert location, nor is there one that serves as the "periphery" [10] (p. 38). Instead, these positions are relative to the community's current culture and what is accepted by the culture as entry and expertise. Despite differences in the orientation of the community, all communities, within 
their respective realms, provide means for the development of members' practice and identity through authentic participation and construction of meaning [13,17].

\subsection{Communities of Practice Share Cultures and Goals}

Communities of practice have been in existence since the first people gathered to share tools, hunting techniques and the survival effort [18]. The concept has been formalized in research over several decades and seen an increase in focus since its beginnings as a mechanism in situated learning and legitimate peripheral participation $[6,9,10,13,18,19]$. The term community of practice has been extensively used in contexts unrelated to the intention of those who first defined it. Lave and Wenger mentioned the conceptualized community of practice in their exposition on situated learning [10]. We view communities now as "groups of people who share concerns, a set of problems, or a passion about a topic and who deepen their knowledge and expertise in this area by interacting on an ongoing basis" [18] (p. 4). Communities are also viewed as venues for collaboration regarding shared interests and means of engaging new members in the existing cultures of a field [20,21].

It is important to note that communities are so natural in their occurrence that they are rarely something of which we are aware $[13,18]$. They take on any number of forms, with the common element being in the framework of "joint enterprise, mutuality and shared repertoire" [6] (p. 229). There is a bonding based on the group comprehension of meaning and responsibility for one another with regard to that meaning, community building through interactions and the sharing of resources that allow members to "negotiate competence through an experience of direct participation" [6] (p. 229). Through the successful navigation of one's respective community from beginner to fully vested practitioner, one gains a position of competence within the field. Zimitat called communities of practice a "continuum of expertise" [21] (p. 322). The existence of communities provides a historical and practical archive of relevant knowledge, meanings, tools and behaviors that provide new members with a method to create their identity as part of the culture through collaboration and cooperation with those who have already established themselves. They are also a continually evolving archival body in that all meaning and practice in the community are "influenced by the community's interactions, not eternally set and followed" [10,13,22].

\subsection{Communities of Practice Exist in Multiple Constructs}

With so many potential directions, it is vital to differentiate among communities of practice, which can be done through examination of their outcomes [22]. Amin and Roberts proposed that there exist four types of communities of practice, "craft/task, professional, expert and online" [17] (p. 7). A craft community of practice would be one where the outcome is the reproduction of a skill or task, for example, Lave and Wenger's notions of traditional apprenticeships where masters train students into a field [10]. Similarly, the professional community of practice is frequently found in higher education institutions, trade schools and job trainings, where formal education is combined with practicum or clinical experiences. Combined experiences that ultimately provide the novice entry into the field while providing experiences through which the novice moves toward expertise and becomes acculturated to the field. Expert communities are those that are more likely to be planned in response to a growing problem or concern that can affect many different existing communities. They are generally made up of higher-competence members from other communities who come together to improve a shared condition through collaboration. Finally, online communities are a newer aspect of communities of practice. They are more difficult to define as the possibilities for distal interactions through venues, from chat rooms to full-scale online communities such as "Second Life," are limitless and open new research horizons [17].

In addressing the constructs of communities of practice, Lave and Wenger explicitly declared that "social category, declared allegiance, belonging to an organization, having a title, or having a personal relationship with some people" [10] (p. 74) does not constitute a community of practice. Furthermore, they are not outlined by who does and does not interact in the day's passing. If all 
three aspects—domain, community and practice-are not present together, then the group is not a community of practice.

\subsection{Communities of Practice are Expert Community Models}

Communities of practice are found everywhere; we are members of many communities that sometimes overlap and interact. Any collection of individuals who join together can become a community of practice as long as there is a shared vision, a combination of resources and reflection to improve practice. Lave and Wenger gave several examples of communities of practice, citing non-academic apprenticeship-style communities [10]. Both formal and informal communities involve learning as a social process. In each case, change occurs through the participation of novice level practitioners in close interaction with experts who willingly share the historical artifacts of the field. The conceptualized visual model demonstrates the possible structuring of communities of practice sought for further study. It is noted that a community does not need to meet every point to be considered.

All communities have three common elements, the domain, which is the "set of issues" or interests that unite the group, the community, those "people who care about the domain," and practice, "what they are developing to be effective in that domain" [18] (p. 27). Domains are demonstrated in the model by three distinct titles: STEM Education and Retention (domain), Expert Practitioners (community) and Outreach and Reform (practice). This particular model represents an expert community. Amin \& Roberts (2006) define these as a community that combines creativity, expertise and value of autonomy, flexibility and personal contribution. Expert communities frequently involve "high-energy peer interactions structured around project-based work" [17] (p. 16). These communities are often made up of leading members from various fields that come together to solve problems that affect all participants. In this case, it refers to members of the broader science, technology, engineering and mathematical (STEM) communities who have shared interests.

Each of the practitioners is considered an expert in their particular field. They seek to form connections between their respective communities and those of others to solve problems by combining knowledge and resources. Some possible domain issues include retention in the STEM fields, resources and support for primary and secondary levels, curriculum and implementation, and cooperative training in content and pedagogy. The outcome of these expert communities is generally a proposed solution to one or more of the problems they address. Outcomes might come in the form of a program, grants to increase resources or fund further study, create partnerships, or be as simple as members having a new understanding or knowledge to take back to their original communities.

In either case, the result of the interactions is some change in practice, whether large or small in scale; learning takes place and resources, everything from shared language and stories to physical artifacts and tools, are developed and shared [6,13]. It is necessary to point out that all interactions produce some form of learning in the members as they interact and share their knowledge and expertise. As Wenger, McDermott and Snyder explained, communities are found in a vast array of forms-they can be any size, be virtual, have fluid boundaries, can be created by natural means or on purpose and may or may not be institutionalized or recognized [18].

\subsection{Communities of Practice Can Become Professional Learning Communities}

The terms professional learning community and community of practice are often mentioned as though the two are interchangeable, but there are subtle points that differentiate the two into separate, but sometimes inclusive concepts. Effective professional learning communities consist of intersecting communities of practice [23]. A community of practice can become a professional learning community if the primary practice involves student learning. Professional learning communities are "a group of educators, prepared and supported to work regularly and collaboratively to develop the necessary knowledge and skills to improve effectiveness and student outcomes" [24]. The original concept of communities of practice was expressed in broad terms to be any group of people who have a shared passion and who come together to improve their understanding and practice of that passion [25]. 
Although the formal definition varies, they are generally acknowledged as groupings of individuals who come together with shared experience, knowledge, and interests [26].

Professional learning communities and communities of practice share many of the same foundations. Both are grounded by the premise that learning is a social occurrence guided by "outcome expectations and perceived self-efficacy" [27]. It is upon this premise that interactions and collaboration are at the forefront of both concepts. They are founded on Lave's premise that knowledge and learning are situated in an authentic context, meaning that learning takes place in real-world situations rather than theoretically through book expositions. Another premise that relates to communities of practice and can be present in individual professional learning communities is the concept of legitimate peripheral participation. The novice, in this case, begins learning on the outer edges of the community and through participation and interaction with experts, becomes a competent member. At the same time, the expert gains greater understanding through teaching the novice. Thus, the two are learning from one another and artifacts are both created and shared within the culture.

\subsection{Professional Learning Communities Target Student Outcomes}

The sole purpose of professional learning communities is the improvement of student learning. Improvement comes through collaboration, many forms of professional development and reflection that ultimately changes approach, practice and vision, but the end game is always student learning. Roberts and Pruitt explained that learning communities are the "vehicle to share ideas about standards-based instruction and assessment in order to "improve learning opportunities and outcomes for students" [28] (pp. 12,15). Communities of practice serve as portals through which new members can begin participating in the community, become immersed in the culture of the community and by participation, acceptance and discourse, become a full member and eventual expert within the scope of the community.

In terms of structure, professional learning communities tend to be more formally organized than communities of practice in that the learning communities involve the formulation of shared goals to solve problems relative to student learning. Communities of practice tend to be more informal collectives of those who have a common practice, such as science, in which artifacts, behaviors and other cultural expectations guide the interactions and assimilation of information. Teachers in learning communities do not decide what knowledge makes up education but rather explore how existing knowledge will be addressed using research-based practices and concepts to best help students. The community of practice is where knowledge that is fundamental to the field is created, accepted or rejected, where practice is defined and enculturation occurs. In essence, the professional learning communities decide how to share and teach the information that is given meaning in the respective communities of practice that define each field of study. In accordance, the inter-related communities of practice within the learning communities provide professional support and identity to the teachers who put their expertise into the overarching learning communities formed within schools.

Professional learning communities have exploded in popularity and commonality as education shifts from the view of the classroom as an island, isolated and disconnected, to that of an inter-related body with nationalized standards, expectations and federal intervention [29]. Many groups have described the learning community, with most in agreement that there is found in these communities a sense of accountability for learning as an outcome [30,31]. Similarly, communities lead to growth and a sense of fellowship in that members encourage and support one another.

Following extensive research on professional learning communities, Kruse, Louis and Bryk outlined five definitive elements to identify professional learning communities [32]. These elements are "reflective dialogue, focus on student learning, interaction among teacher colleagues, collaboration and shared values and norms" [28] (p. 7). However, it is noted that the actual appearance may vary [29]. Within itself, the professional learning community is a "cultural setting" in which social learning takes place to impart growth across levels of membership. Each member is responsible for the learning and overall well-being of everyone else and is as focused on the change and adoption of culture as they are about the learning process $[29,33]$. It is important to note that the creation and sustenance of 
professional learning communities requires effort and change. The essence of learning communities is often in direct conflict with the traditional notions of teaching, practice and development that have dominated public education [34].

\section{Discussion-Building Professional Learning Communities in Communities of Practice}

Communities of practice can be found anywhere practice is being defined and identity constructed, such as higher education institutions. The scientific community is made up of smaller communities of practice in which the disciplines conduct research, set the norms for practice in the field that contribute to identity as a scientist and generally work together to solve problems, prove and disprove theories and expand the understanding of the natural world. In this context, communities of practice are highly competitive bodies in which participation requires a type of indoctrination from novice to expert, all in the context of demonstrating ability to peers to gain acceptance. Professional learning communities are more likely to be found at the primary and secondary levels of education where research is being applied to practice to improve student outcomes and where "competition is de-emphasized" [35]. It might be said that professional learning communities occur in the "trenches" in that the members are on the front lines, sharing strategies, practicing techniques and continually reflecting on data to provide students with the best learning experiences for each topic and subject. In education, learning communities and communities of practice are integral parts of learning that emphasize the social nature of the human learning process.

The structural elements required by professional learning communities are closely aligned with those mentioned before in the discussion of study groups. Kruse, Louis and Bryk explain that time and interactions are of considerable importance [32]. In addition to ample time for discourse and collaboration, the members of a learning community need in-person or proximal interactions. They explained that members must be in a position to rely on one another and have complementary roles in that their field or station connects in some way to the other members of the community, whether by similar content, practice or interdisciplinary application. In addition to physical contact, open communication among members must be established and continually enabled so that interactions are encouraged and dialogue supports growth. Finally, teachers must be empowered by the administration and like systems to take on leadership roles to reflect upon and improve practice in their central settings.

DuFour, Eaker and DuFour address three conditions that must continually be met by groups for them to qualify as professional learning communities [34]. Primarily these bodies must demonstrate the ability to generate collaborative knowledge and put it to use in institutions, which, as they describe, have been a component missing from many organizations claiming to be learning communities [34] (p. 9). Another concern is the maintenance of learning communities to ensure that change and reflection are continual and do not cease, a task they admit requires much energy and effort. Finally, learning communities are not mandated meetings or groups and they cannot be forced or contrived. The creation of learning communities requires a change in the very culture of the institution, a task that causes a realignment of goals, roles and expectations that have been prevalent in institutional culture for decades and work in direct opposition to collaborative reform.

\section{Conclusions}

STEM education represents a variety of challenges, including the involvement of four (or more, depending on the acronym-STEAM, STEMM) distinct fields of study. Often STEM is simplified into cross-talk - how math is the language of science, how both come into play in engineering - but true integration and authentic connection are missing. At the university level, particularly, the distinction of the disciplines is pronounced due to the principle of ownership. While some institutions may house math and science within a shared cohort or similarly situate engineering and technology, the four are often housed in distinct units with separated leadership, missions, goals and expectations. When the education component is added, we frequently have widely varying fields of expertise with a shared goal but very different perceptions of approaches and implementation. 
While STEM education is not new, there is still much work needed to define the field clearly, increase interest and retain students [1-4]. While individual changes and actions are essential, it is at the community level, where change is sweeping, and sustainability becomes possible [2,35]. Although there are existing large-scale communities of practice working toward change in STEM and STEM education, there is still a need for more of these communities. Reaching the success level needed to entice and retain students and ensure their experiences are preparing them for the realities of the field requires large-scale impact [5]. Leveraging communities of practice toward student impacts and outcomes shifts communities of practice from field-based expert communities into professional learning communities. While the two are similar and can be complementary, awareness of the differences in structure, purpose and intended outcomes is essential to the creation, maintenance and sustainability of these intersecting communities. By definition, learning communities are social entities, bringing together more than just experts by including peers, students and professionals in ways that allow each to learn from the others [36]. Leveraging these communities in both formal and informal ways can impact retention and engagement in STEM and lead to larger-scale reform across STEM education [5,37].

Funding: This research received no external funding.

Conflicts of Interest: The author declares no conflict of interest.

\section{References}

1. Borrego, M.; Henderson, C. Increasing the use of evidence-based teaching in STEM higher education: A comparison of eight change strategies. J. Eng. Educ. 2014, 103, 220-252. [CrossRef]

2. Gehrke, S.; Kezar, A. The roles of STEM faculty communities of practice in institutional and departmental reform in higher education. Am. Educ. Res. J. 2017, 54, 803-833. [CrossRef]

3. Henderson, C.; Beach, A.; Finkelstein, N. Facilitating change in undergraduate STEM instructional practices: An analytic review of the literature. J. Res. Sci. Teach. 2011, 48, 952-984. [CrossRef]

4. Singer, S.R.; Nielsen, N.R.; Schweingruber, H.A. Discipline-Based Education Research: Understanding and Improving Learning in Undergraduate Science and Engineering; National Research Council of the National Academies of Science: Washington, DC, USA, 2012.

5. Kezar, A.; Gehrke, S.; Bernstein-Sierra, S. Designing for success in STEM communities of practice: Philosophy and personal interactions. Rev. High. Educ. 2017, 40, 217-244. [CrossRef]

6. Wenger, E. Communities of practice and social learning systems. Organizations 2000, 7, 225-248. [CrossRef]

7. American Association for Advancement of Science. Vision and Change in Undergraduate Biology Education: A Call to Action; American Association for Advancement of Science: Washington, DC, USA, 2010. Available online: http://visionandchange.org/files/2013/11/aaas-vischange-web1113.pdf (accessed on 7 April 2020).

8. Anderson, C.W. Perspectives on science learning. In Handbook of Research on Science Education; Abell, S.K., Lederman, N.G., Eds.; Lawrence Erlbaum Associates, Inc.: Mahwah, NJ, USA, 2007; pp. 3-30.

9. Lave, J.; Murtaugh, M.; de la Rocha, O. The dialective of arithmetic in grocery shopping. In Everyday Cognition; Its Development in Social Context; Rogoff, B., Lave, J., Eds.; Harvard University Press: Cambridge, MA, USA, 1984; pp. 67-94.

10. Lave, J.; Wenger, E. Situated Learning: Legitimate Peripheral Participation; Cambridge University Press: Cambridge, UK, 1991.

11. Tobin, K.; Tippins, D. Constructivism as a referent for teaching and learning. In Constructivism: The Practice of Constructivism in Science Education; Tobin, K., Ed.; Lawrence Erlbaum Associates, Inc.: Hillsdale, NJ, USA, 1993; pp. 3-21.

12. Woods, P. Symbolic interaction: Theory and method. In The Handbook of Qualitative Research in Education; Lecompte, M.D., Millroy, W.L., Preissle, J., Eds.; Academic Press, Inc.: San Diego, CA, USA, 1992; pp. 337-404.

13. Wenger, E. Communities of Practice: Learning, Meaning, and Identity; Cambridge University Press: Cambridge, UK, 1998.

14. Carlsen, W.S. Language and science learning. In Handbook of Research on Science Education; Abell, S.K., Lederman, N.G., Eds.; Lawrence Erlbaum Associates, Inc.: Mahwah, NJ, USA, 2008; pp. 57-74. 
15. Johnson, C.M. A survey of current research on online communities of practice. Internet High Educ. 2001, 4, 45-60. [CrossRef]

16. Wallace, A.F.C. Culture and Personality, 2nd ed.; Random House: New York, NY, USA, 1970.

17. Amin, A.; Roberts, J. Communities of Practice? Varieties of Situated Learning. Retrieved from the European Union, Network of Excellence, Dynamics of Institutions and Markets in Europe (DIME). 2006. Available online: http://www.dime-eu.org/files/active/0/Amin_Roberts.pdf (accessed on 7 April 2020).

18. Wenger, E.; Mcdermott, R.; Snyder, W.M. Cultivating Communities of Practice: A Guide to Managing Knowledge; Harvard Business School Press: Boston, MA, USA, 2002.

19. Brown, J.S.; Duguid, P. Organizational learning and communities-of-practice: Toward a unified view of working, learning, and innovation. Organ. Sci. 1991, 2, 40-57. [CrossRef]

20. Weaver, L.D.; Pifer, M.J.; Colbeck, C.L. Janusian leadership: Two profiles of power in a community of practice. Innov High. Educ. 2009, 34, 307-320. [CrossRef]

21. Zimitat, C. Capturing community of practice knowledge for student learning. Innov. Educ. Teach. Int. 2007, 44, 321-330. [CrossRef]

22. Cox, A. What are communities of practice? A comparative review of four seminal works. J. Inf. Sci. 2005, 31, 527-540. [CrossRef]

23. Cate, J.M.; Vaughn, C.A.; o'hair, M.J. A 17-year case study of an elementary school to learning community to democratic school community. J. Sch. Leadersh. 2006, 16, 86-111. [CrossRef]

24. Dufour, R.; Eaker, R. Professional Learning Communities; National Educational Service: Bloomington, IN, USA, 1998.

25. Wenger, E. Communities of Practice: An Introduction. 2006. Available online: https:/pdfs.semanticscholar.org/84d6/ e4deccf799fbc18c6a2b7a86911e62cbe78d.pdf?_ga=2.24733887.48493505.1595382913-2055625631.1595382913 (accessed on 6 January 2013).

26. Breu, K.; Hemingway, C. The power of communities-of-practice for subverting organisational change. In Proceedings of the Third European Conference on Organisational Knowledge, Learning and Capabilities, Athens, Greece, 5-6 April 2002; pp. 4-6.

27. Smylie, M.A. Teacher learning in the workplace: Implications for school reform. In Professional Development in Education: New Paradigms and Practices; Guskey, T.R., Huberman, M., Eds.; Teachers College Press: New York, NY, USA, 1995; pp. 92-113.

28. Roberts, S.; Pruitt, E. Learning through ongoing professional development. In Schools as Professional Learning Communities; Corwin Press: Thousand Oaks, CA, USA, 2009; pp. 51-70.

29. Mundry, S.; Stiles, K.E. Professional Learning Communities for Science Teaching: Lessons from Research and Practice; NSTA Press: Arlington, VA, USA, 2009.

30. Collay, M.; Dunlap, D.; Enloe, W.; Gagnon, G.W., Jr. Learning Circles: Creating Conditions for Professional Development; Corwin Press: Thousand Oaks, CA, USA, 1998.

31. Senge, P.M. The Art and Practice of the Learning Organization; Random House Business: New York, NY, USA, 1990.

32. Kruse, S.; Louis, K.S.; Bryk, A.S. Building Professional Community in Schools; Center on Organization and Restructuring of Schools: Madison, WI, USA, 1994.

33. Myers, C.B.; Simpson, D.J. Re-Creating Schools: Places Where Everyone Learns and Likes It; Corwin Press: Thousand Oaks, CA, USA, 1997.

34. Dufour, R.; Eaker, R.; Dufour, R. (Eds.) Closing the knowing-doing gap. In On Common Ground: The Power of Professional Learning Communities; National Educational Service: Bloomington, IN, USA, 2005; pp. 225-254.

35. Zhu, E.; Baylen, D.M. From learning community to community learning: Pedagogy, technology and interactivity. Educ. Media Int. 2005, 42, 251-268. [CrossRef]

36. Carrino, S.S.; Gerace, W.J. Why STEM Learning Communities Work: The Development of Psychosocial Learning Factors Through Social Interaction. Learn. Communities Res. Pract. 2016, 4, 3.

37. Dagley, M.; Georgiopoulos, M.; Reece, A.; Young, C. Increasingretention and graduation rates through a STEM learning community. J. Coll. Stud. Retent. Res. Theory Pract. 2015. [CrossRef] 